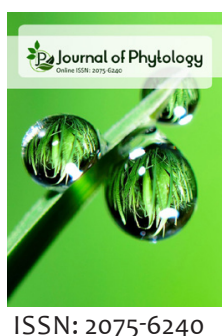

Received: January 01, 2021 Revised: April 20, 2021 Accepted: April 23, 2021 Published: April 29, 2021

*Corresponding Author: M. Arumugam, E-mail: aarubot@gmail.com

\section{Green synthesis of silver nanoparticles using Indigofera cordifolia leaf extract and their pharmacological potential}

\author{
P. K. Siva', M. Sathish', T. Parvathi', M. Kamaraj ${ }^{2}$ R. Bhuvaneswari ${ }^{3}$, \\ M. Arumugam ${ }^{1 *}$
}

${ }^{1}$ PG and Research Department of Botany, J.J College of Arts and Science (Autonomous), Pudukkottai, Tamil Nadu - 622 422, India, ${ }^{2}$ PG and Research Department of Botany, Jamal Mohamed College (Autonomous), Tiruchirapalli-620 020, Tamil Nadu, India, ${ }^{3}$ PG and Research Department of Physics, Government Arts College for Women (Autonomous), Pudukkottai-622001, Tamil Nadu, India (1,2,3Affiliated to Bharathidasan University, Thiruchirappalli, Tamil Nadu-620024-India)

\begin{abstract}
Biologically the silver nanoparticles were synthesized from Indigofera cordifolialeaves extract. The absorbance of the silver nanoparticles centered at four hundred and twenty nm, with respect to the surface plasmon resonance of silver nanoparticles wavelength. XRD method proves, biosynthesized NPs would retain the face centered cubic (fcc) structure. In TEM image analysis, silver NPs morphology was spherical in shape. Composition of the silver nanoparticles was obtained by EDAX analysis method. FTIR analysis concluded that biosynthesis Ag NPs was observed at $1384 \mathrm{~cm}^{-1}$, with respect to $-\mathrm{NO}_{3}$ stretching arises from $\mathrm{AgNO}_{3}$. Ten types of bands are present in the broad emission because of organic matrix bound to silver nanoparticles, which reveals as the result of photoluminescence measurements. The silver NPs possess more antibacterial activity as compared to the standard drug, Amoxicillin.
\end{abstract}

KEYWORDS: Indigofera cordifolia, Silver nanoparticle, Green synthesis, Plasmon resonance, X-Ray Diffraction, Antibacterial activity

\section{INTRODUCTION}

The green synthesis methods which are eco friendly methods in the field of science and technologies are very much popular in the future and these methods are essential to minimize the issues in agriculture (Thuesombat et al., 2014). The biological production of silver nanoparticles consist of three major stages, the process must studied on the basis of green chemistry perspective, they are selection of solvent medium, reducing agent that are environmentally non invading tumors, and nontoxic substances for the stability of Ag NPs.

Indigofera tinctoria L. belongs to the family Fabaceae, its synonym is Indigofera sumatrana Gaertn. Leaves of the plant are medicinally related. The plant is a shrub, flowering occurs in August to December. The plant is empirical in tainted forest areas and scrub jungles, also in the plains. The plant is spread in Paleotropics, widely cultivated in every districts of Kerala. Local names are Amari, Neelayamari. It is a subshrub, originate in moist deciduous forests and also in plains, the plant is widely cultivated (Sasidharan, 2004). Indigofera tinctoria is used in constipation, liver disease, heart palpitation and gout
(Amrithpal , 2006). The roots, stems and leaves are used for treating chronic bronchitis, asthama, ulcers, skin diseases and is useful for promoting growth of hair. The juice extracted from the leaves is useful in the treatment of hydrophobia. An extract of the plant is high-quality for epilepsy and neuropathy. The plant possesses anti-toxic property (Warrirer et al., 2007). The flavonoid fraction of Indigofera tinctoria had chemopreventive effect against benzeo pyrene induced lung cancer (Ravichandran \& Ravichandran, 2008). The tangential analgesic possessions of Indigofera tinctoria was reported Saravanakumar, 2009. The methanolic extract of the entire plant possessed antihelmintic activity against Pheretima posthuma (Gunasekaran, et al., 2009). The ethanolic leaf extract Indigofera tinctoria have the ability to inhibit the growth of gram positive bacteria namely Bacillus pumilus, Staphylococcus aureus and Streptococcus pyrogens. Strong antioxidant activity was experiential both qualitatively and quantitatively. The cytotoxic effect of Indigofera tinctoria leaf extract on lung cancer cell line NCIH69 was studied. The proportion cell viability of cells was found to decrease at increasing attentiveness (Renukadevi \& Sultana, 2011). present work, AgNPs are synthesized Indigofera cordifolia leaf extract using a green approach. We identified the morphological

Copyright: $\odot$ The authors. This article is open access and licensed under the terms of the Creative Commons Attribution License (http://creativecommons.org/licenses/by/4.0/) which permits unrestricted, use, distribution and reproduction in any medium, or format for any purpose, even commercially provided the work is properly cited. Attribution - You must give appropriate credit, provide a link to the license, and indicate if changes were made. 
properties, optical properties and antimicrobial activities of NPs of Ag. This is the primary study in the NPs of Ag on green production from Indigofera cordifolia leaves extract. Subjected studies like UV-Visible, X-Ray diffraction, XPS, FESEM, EDAX, Fourier transform IR spectroscopy, photoluminescence and antimicrobial property studies.

\section{MATERIALS AND METHODS}

\section{Green Synthesis of Silver Nanoparticles}

Indigofera cordifolia leaves were collected from Musiri (10.9549 $\mathrm{N}, 78.4439^{\circ} \mathrm{E}$ ) Tiruchirappalli (Tamil Nadu, India) and used for the preparation of the aqueous extract and it was subjected to extraction. The exact preparations consisted of different steps. The primary step was cleaning the plant leaves with fresh water, again washed with demineralized water and then cut into tiny parts. $10 \mathrm{~g}$ of perfectly crushed plant leaves were added to hundred milliliters of double demineralized water. Then it vaporized for ten minutes at $80^{\circ} \mathrm{C}$. The final product was extracted by using filter paper (Whatman no.1). The filtrate was collected and kept in the $250 \mathrm{~mL}$ Erlenmeyer flask. It was kept at room temperature and used for further analysis. 50 milliliter of the prepared extraction was mixed with 50 milliliters of 1 millimolar Silver nitrate solution at room temperature. Then the Silver nanoparticles were evidently identified after twenty minutes.

\section{Characterization Techniques}

The silver nanoparticles were characterized by XRD, XPS and FESEM analysis Angles between $30^{\circ}-80^{\circ}$ for and the monochromatic wavelength of $1.54 \AA$ were applied for the nanoparticles. The Fourier-transform infrared spectroscopy would be measured on a range of four hundred to four thousand $\mathrm{cm}^{-1}$ in the Perkin-Elmer spectrometer. The electromagnetic spectrum of silver nanoparticles was identified in wavelength between $200 \mathrm{~nm}$ to $1100 \mathrm{~nm}$ by Lambda 35 spectrometer. The photoluminescence spectra were identified by the Perkin Elmer-LS 14 spectrometer.

\section{Antibacterial Assay}

The antimicrobial activity of the AgNPs were determined by the well diffusion assay on MHA towards Klebsiella pneumonia, Streptococcus aureus, Shigella dysenteriae, Escherichia coli, Pseudomonas aeruginosa, Staphylococcus pneumonia and Pseudomonas vulgaris. For the antibacterial assay, Molten Nutrient Agar (MHA) plates were prepared and it streaked with bacterial inoculum for two to three times. During streaking, the MHA plates were rotated at a sixty degree angle the uniform distribution of the bacterial inoculum on the plates. After the inoculation of the microorganism on the plate disc with different concentrations are placed on the inoculated agar plate. The test sample concentrations include $40 \mu \mathrm{l} / \mathrm{ml}$ (loaded for $1.5 \mathrm{mg}$ ) and $50 \mu \mathrm{l} / \mathrm{ml}$ (loaded for $1.75 \mathrm{mg}$ ), which are loaded in the wells on the inoculated MHA plate. The MHA plated were subjected to incubation, the plates were placed on the incubator for twenty four hours at thirty seven ${ }^{\circ} \mathrm{C}$. After the incubation zone will be formed around the disc and that is called the zone of inhibition, it measure and also record. Amoxicillin (Hi-Media) antibiotic disc were used as positive control for Klebsiella pneumoniae, Streptococcus aureus, Shigella dysenteriae, Escherichia coli, Pseudomonas aeruginosa, Staphylococcus pneumonia and Pseudomonas vulgaris corresponding to as compared the capacity of the particular test sample. Dimethyl sulfoxide used as the result with negative action. It was found that dimethyl sulfoxide does not show biochemical possessions.

\section{Cell Culture}

Dulbecco's modified Eagle's medium, DMEM having the $\mathrm{pH}$ of 7.2 to which $10 \%$ FBS was supplemented were introduced for the cultivation of breast cancer MCF-7 cells. The culture media also treated by using gentamicin $(100 \mathrm{U} / \mathrm{mL})$ to reduce the contamination. An incubator with high moisture content having 5\% carbon dioxide was proposed for the incubation of breast cancer cell. From the cell culture the $80-90 \%$ cells were collected by the use of trypsin. Then it was washed with phosphate buffered saline.

\section{Cell Viability Assays}

The viability of the cells was identified by using the slightly altered protocol of MTT cytotoxicity assay (Raveendran et al., 2003). The cultured breast cancer cells would be developed to density of $2 \times 10^{4}$ cells/wells for 24 hrs. Introduced to various test concentrations of silver nanoparticles for $24 \mathrm{hrs}$. After the treatment phosphate buffered substrate with added $5.0 \mathrm{mg} / \mathrm{mL}$ MTT were introduced at the range of 10 microliter into each well and incubated for another 4 hrs. The transfer of MTT leads to the development of formazan crystals inside the hepatic cells. Dimethyl sulfoxide $(100 \mu \mathrm{L})$ was treated with the formazan crystals which dissolved. The measurements were taken at $570 \mathrm{~nm}$. ELISA readers (BioTek) were used to taking readings.

\section{RESULTS AND DISCUSSION}

\section{UV-Vis Spectroscopic Studies}

The Indigofera cordifolialeaf extract was used in the reduction of $\mathrm{AgNO}_{3}$ into $\mathrm{Ag}^{0}$, and the reduction was initially confirmed by the color changes from colorless to yellowish brown color is shown in Figure la. On the basis of the arrangement of the size of the NPs, the produced Ag NPs manifest the absorbance between $400 \mathrm{~nm}$ to $450 \mathrm{~nm}$. Then the absorbance of the nanoparticle will be centralized at $420 \mathrm{~nm}$ peak.

The relationship of $\alpha$ and hu can be expressed as,

$$
\alpha h v=A\left(h v-E_{g}\right)^{n}
$$

Where, absorption coefficient is alpha, hv, incident photon energy, $\mathrm{E}_{\mathrm{g}}$, optical band gap, $\mathrm{A}$, constant, $\mathrm{n}$ is the exponent. 


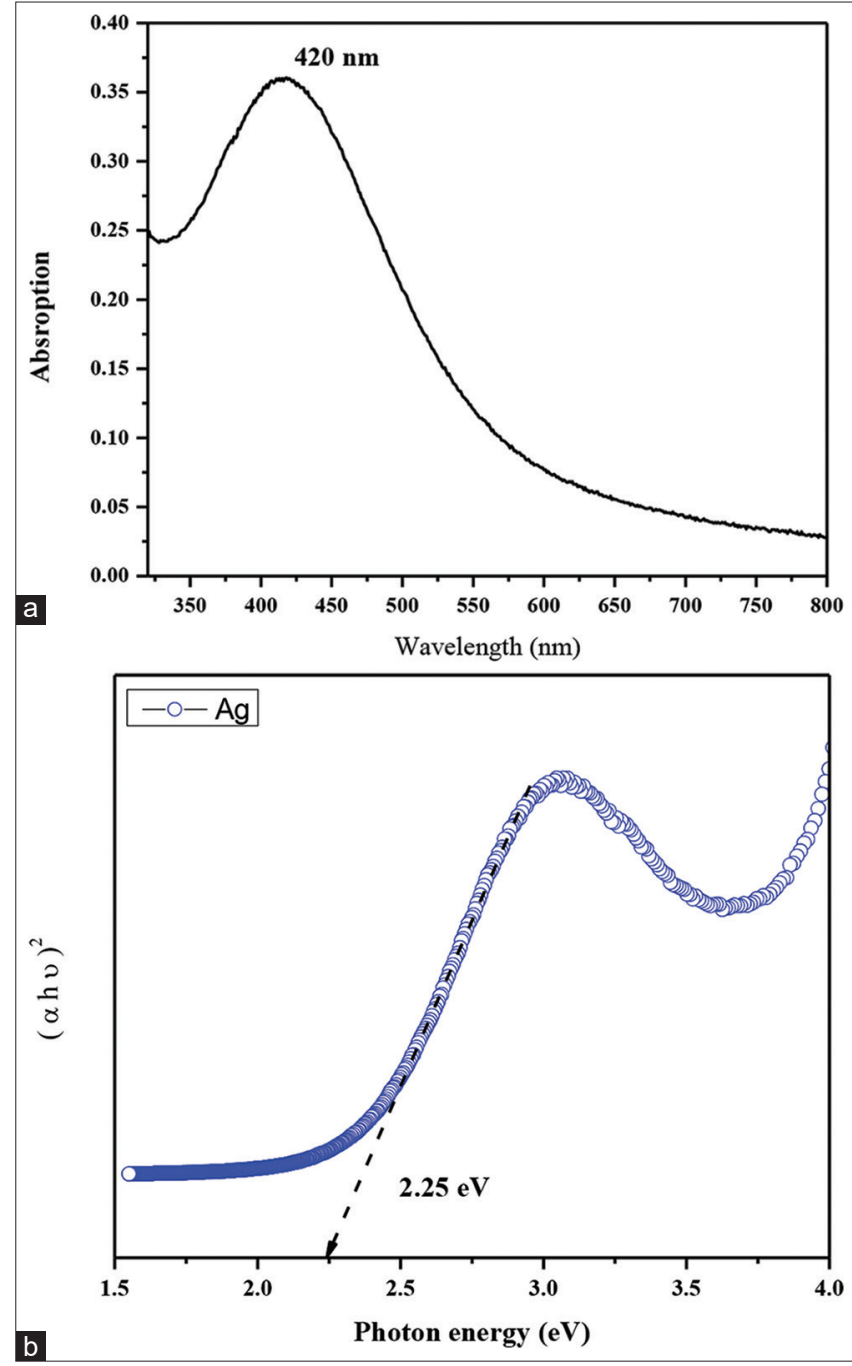

Figure 1: (a) UV-Vis spectrum of Ag NPs synthesized by Indigofera cordifolia leaf extract. (b) Photon energy level of the phyto-synthesized silver NPs

Allowed direct transition occurs when the value of $n$ becomes half. A plot is drawn between $(\alpha h v)^{2}$ vs. photon energy, hv for determining the direct and indirect transition and to find the intercept with energy axis, a linear portion of the edge is extrapolated (Figure lb) At $2.25 \mathrm{eV}, \mathrm{Ag}$ NPs direct band gap is observed.

\section{X-ray Diffraction Studies}

The XRD pattern of Ag NPs are synthesis from Indigofera cordifolialeaf extraction is presented in Figure 2. The X- Ray diffraction patterns are shows at $(2 \theta)$ of $38.02,43.99,64.48$ and 77.31 with respect to various plane $(111,200,220$ and 311$)$ of the Ag nanoparticles. The standard peaks on the graph represent the face-centered cubic of Ag Nanoparticles. XRD represents the Ag NPs generated due to the $\mathrm{Ag}^{+}$ion reduced by the leaf extract of Indigofera cordifolia

The lattice constant 'a' of silver found from this equation,

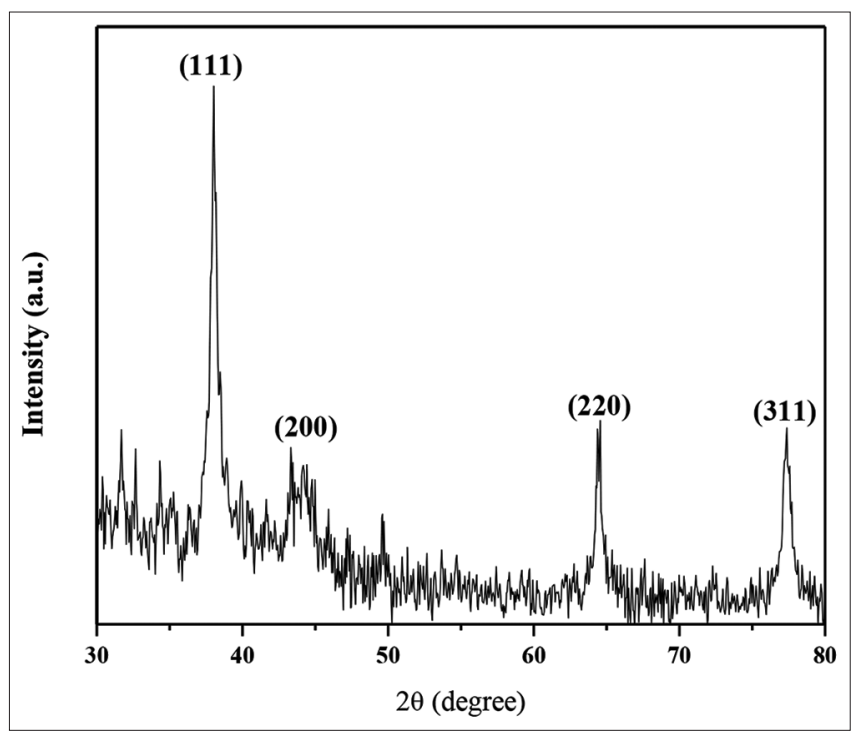

Figure 2: Diffraction patterns (X-ray) of synthesized silver nanoparticles

$$
\frac{1}{d^{2}}=\left(\frac{h^{2}+k^{2}+l^{2}}{a^{2}}\right)
$$

' $\mathrm{a}$ ' is the lattice constant obtained from the formula, $\mathrm{a}=\sqrt{ } \mathrm{d}^{2}\left(\mathrm{~h}^{2}+\mathrm{k}^{2}+\mathrm{l}^{2}\right)$. Estimated value of ' $\mathrm{a}$ ' is $4.0993 \AA$ for silver nanoparticles. The unit cell volume calculated from the above mentioned relation is $V=a^{3}$. $V$ is identified as $68.8857 \AA^{3}$ for silver nanoparticles.

Debye-Scherrer's formula used to find D,

Where D is Average crystallite size of a nanoparticle.

$$
D=\frac{0.9 \lambda}{\beta \cos \theta}
$$

Here, X-ray wavelength is represented as $\lambda$, the angular peak width at half maximum in radians is indicated as beta and Bragg's diffraction angle is $\theta$. For Ag NPs the value (D) obtained is $28.46 \mathrm{~nm}$.

\section{X-ray Photoelectron Spectroscopy Analysis}

The X-ray photoelectron spectra gives the knowledge of the oxidation state of $\mathrm{Cls}, \mathrm{Ols}$ and silver $3 \mathrm{~d}$ state for silver nanoparticles synthesized by Indigofera cordifolia leaf extract is represented in Figure 3(a-c). Figure 3a shows the Cls signal split into three symmetric peaks observed at $(284.30 \mathrm{eV}$, $286.59 \mathrm{eV}$ and $294.06 \mathrm{eV}$ ). The carbon $\mathrm{Cls}$ peck center at $284.30 \mathrm{eV}$ associated with C-C state, in contrast to carbon atoms of Tyr, Trp or Phe phenyl rings. The carbonyl carbons C-O peak is observed at $286.59 \mathrm{eV}$ for Ag NPs and were attributes to transfer of electron from carbons in carbonyl groups and Finally $\mathrm{O}-\mathrm{C}=\mathrm{O}$ peak center at $294.06 \mathrm{eV}$, which was most likely from carbons a to the carboxylic groups 
for silver NPs synthesized by using Indigofera cordifolialeaf extract (Li et al., 2007). Figure 3b indicates oxygen (1s) non symmetrical signal differentiated into two identical signal are obtained at $527.98 \mathrm{eV}$ and $530.12 \mathrm{eV}$ for Ag NPs, which is described to the carboxylate groups (Li et al., 2007). Figure 3c represents the strong spin orbit coupling where the $\mathrm{Ag}(3 \mathrm{~d})$ signal splits into two identical peaks $\mathrm{Ag} 3 \mathrm{~d}_{5 / 2}$ and $\mathrm{Ag} 3 \mathrm{~d}_{3 / 2}$. The silver nanoparticles, which peak in the graph, were situated at $367.57 \mathrm{eV}$ and $373.63 \mathrm{eV}$. The spin-orbit split value was 6.06 $\mathrm{eV}$ which collaborated with the binding energy of metallic Ag (Kaushik, 1991). At last the ions of silver get changed to its metallic form $(\mathrm{Ag})$. The bio Ag nanoparticles were capped by the extracts of Indigofera cordifolia.

\section{The Morphology and Elemental Composition}

The surface structure of the silver nanoparticles are produced from Indigoferacordifolialeaf extract is represented in Figure 4(a-b). The complete Field Emission Scanning Electron Microscopic image, the silver NPs is formed spherical shape. The elemental composition of the nanoparticle obtained by Energy Dispersive X- ray analysis spectra of the silver nanoparticles arerepresented in Figure 5. These spectra displayed the presence of $\mathrm{C}, \mathrm{O}$, and $\mathrm{Ag}$ in silver NPs using Indigofera cordifolia leaf extract.

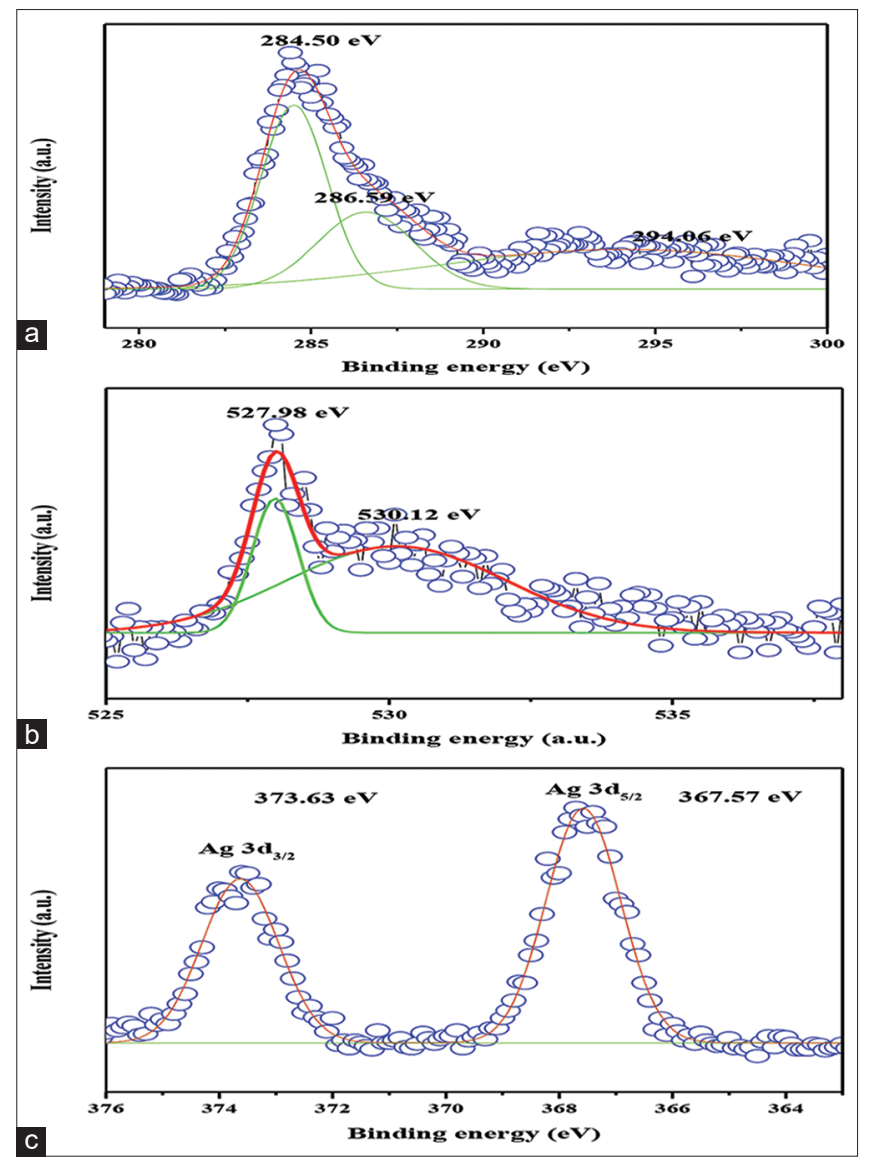

Figure 3: (a) XPS spectra of C (1s) for the silver NPs. (c) XPS spectra of $\mathrm{Ag}(3 \mathrm{~d})$ for the silver NPs, 3b: XPS spectra of O (1s) for the silver NPs

\section{High Resolution Transmission Electron Microscopic Studies}

Figure 6 represents that the HRTEM image of Ag Nanoparticles is produced from Indigofera cordifolia leaf extract. Silver NPs possessed a spherical structure, in a size range of 10-30 nm. SAED patterns can be assigned to the reflections $(111,200$, 220 and 311) for Si and Ag NPs respectively.

\section{FTIR Spectroscopic Studies}

The extract was prepared from the plant which has two major functions such as capping and reducing properties. The availability of functional groups were discovered by Fourier transform infrared analysis of Ag NPs. Figure 7 (a-b) shows the FTIR spectra for Ag nanoparticles were synthesized by Indigofera cordifolia leaf extract. The broad absorption band is observed at $3464 \mathrm{~cm}^{-1}$ in the silver sample and this vibration frequency is bounded hydroxyl $(-\mathrm{OH})$ or amine (-NH) groups present in the bio-macromolecules on leaf extract (Shah et al., 2016) [5]. In literature C-H stretching of methyl groups vibration were observed at 2962 and $2873 \mathrm{~cm}^{-1}$ for silver NPs. In our result, C-H stretching of methyl group's vibration is observed at2972 and $2867 \mathrm{~cm}^{-1}$ for silver NPs. From the Fourier transform infrared spectra of green synthesis silver nanoparticle vibration frequency are identified at $1384 \mathrm{~cm}^{-}$ ${ }^{1}$ with respect to $-\mathrm{NO}_{3}$ stretching which comes from silver nitrate (Coates and Meyers, 2000; Edison et al., 2016). The C-H bending vibration identified at $839 \mathrm{~cm}^{-1}$ for silver nanoparticles. The metallic silver graph's peak obtained at

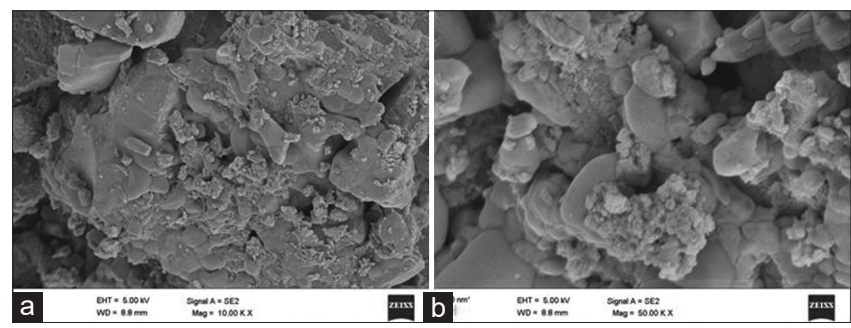

Figure 4: (a-b) Field Emission Scanning Electron Microscopy image of high and low magnification for silver NPs.

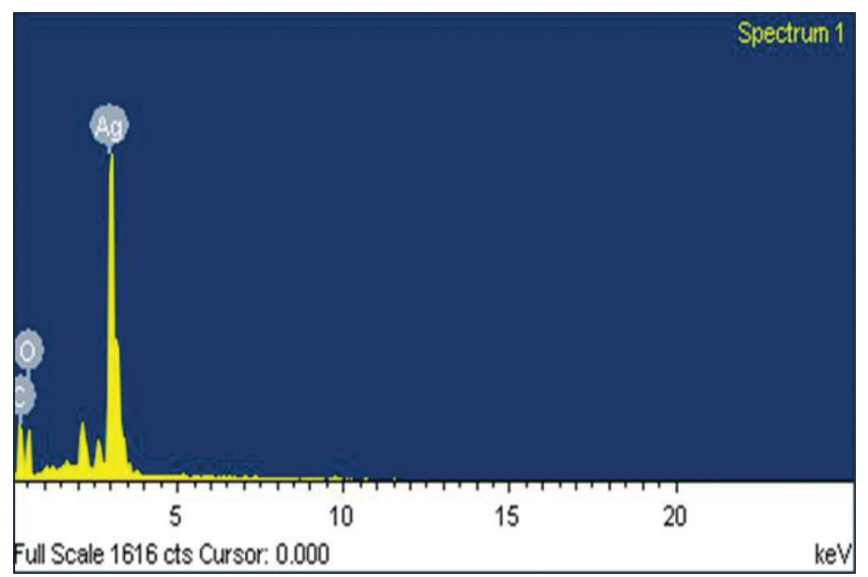

Figure 5: EDAX spectra of the silver NPs 

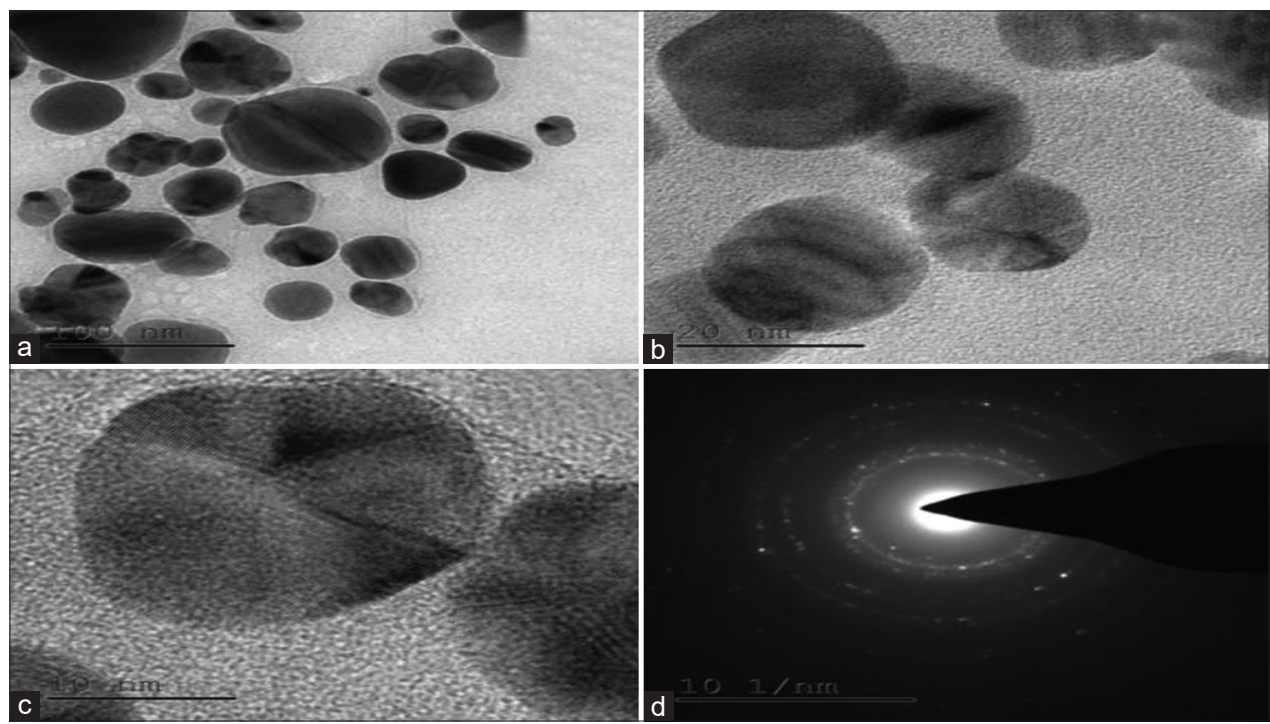

Figure 6: (a-c) High and low magnifications of silver NPs and (d) SAED pattern of silver NPs

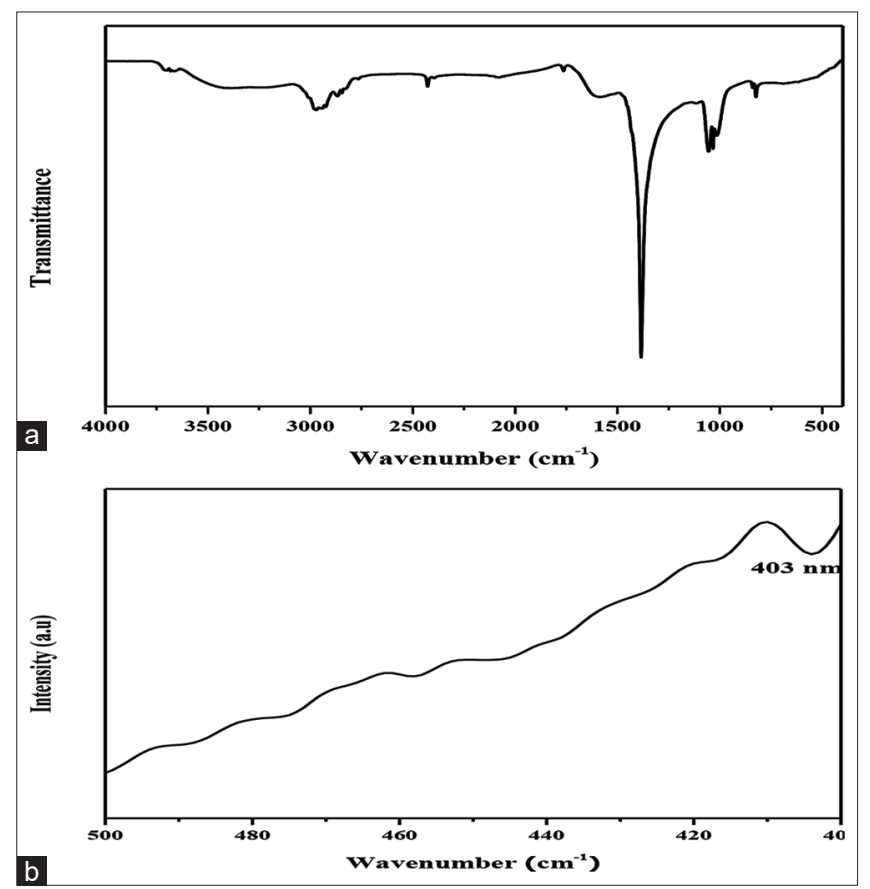

Figure 7: (a) FTIR spectra of silver NPs. (b) Extended 500-400 cm${ }^{1}$ region of FTIR spectra for silver NPs

$403 \mathrm{~cm}^{-1}$ for Ag nanoparticles are synthesis from Indigofera cordifolia leaves extract (Figure 7b.).

\section{Photoluminescence spectroscopic studies}

Photoluminescence (PL) spectra are one of the effective tools to identify the optical activity of Ag NPs as photonic materials. Synthesized silver NPs using Indigofera cordifolia leaf extract is present in Figure 8. The excitation wavelength of silver nanoparticles is identified at $420 \mathrm{~nm}$. The emission spectrum of the silver nano particle with six peaks is observed at $448 \mathrm{~nm}, 480$ nanometer, 491 nanometer, 501 nanometer, 541 nanometer and

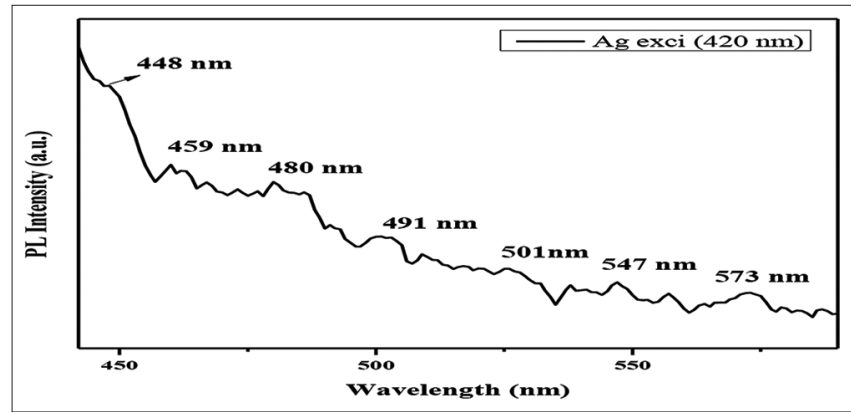

Figure 8: Photoluminescence spectra of silver NPs

573 nanometer. The two blue emission, blue-green emission, two green emission and yellow emission for silver NPs. The luminescence emission peaks at 440 and 600 nanometer shows because of the availability of antioxidant in Indigofera cordifolia plant extract. The green emission and yellow peaks at $501 \mathrm{~nm}$, $541 \mathrm{~nm}$ and $573 \mathrm{~nm}$ of the organic matrix bound to silver nanoparticles.

\section{Antibacterial Studies}

In present work, silver NPs synthesized by Indigofera cordifolia leaf extract is treated with $S$. aureusand $S$. pneumoniae and E. coli, Pseudomonas aeruginosa, P. vulgaris, K. pneumoniae and $S$. dysenteriae analyzed well diffusion assay represented in Figure 9. The antimicrobial activity examined around the all-well concentration $(20,25,30$ and $35 \mu \mathrm{g} / \mathrm{ml})$ of silver nanoparticles treated with test samples (Table 1). The zone inhibition of silver NPs possesses more antibacterial activity as compared to standard Amoxicillin (10 $\mu \mathrm{g}$ disc). Increasing silver nanoparticles concentrations, zone inhibition also increased. The nanoparticles synthesized from plant extract that act against the microorganisms by the production of secondary metabolites which is responsible for the inhibition of the microorganisms. The Ag NPs having large surface area which is the largest capacity of the particular nanoparticle against 
the microbial cells. The NPs which bound with the plasma membrane of the bacterial cell and moves into the cytoplasm of the microorganism (Wang et al., 2017; Sirelkhatim et al., 2015; Mohd Yusof et al., 2019; Liao et al., 2019; Sánchez-López et al., 2020). The microorganisms surface that bound with the $\mathrm{S}$ - containing membrane proteins. The AgNPs were act with the membrane proteins and also act with the Phosphorus containing Deoxyribonucleic acid.

The nanoparticles major advantage is its size, the nanoparticles are tiny particles which has high surface area which can actively react with the microorganisms. The nanoparticles have high efficiency than larger particles (Rai et al., 2009). In our result, silver nanoparticles average size less than $10-30 \mathrm{~nm}$ that will increase the activity of NPs by acting with the microorganism and there by producing the electronic effect (Rai et al., 2009). From the photoluminescence spectra of the silver NPs, the wavelengths of the green and yellow lights are $501 \mathrm{~nm}, 547$ $\mathrm{nm}$ and $573 \mathrm{~nm}$ for the Ag nanoparticles only because of the availability of $\mathrm{O}$ vacancy. So that the silver NPs have more antimicrobial activity.

MTT cell viability assay were used to find the cytotoxic property of AgNPs in MCF-7 cells (Table 2). Different concentrations of MCF-7 cells were prepared and the inhibition percentage was identified with the help of cells without mixed with the nanoparticles. It is clear that the concentration needed to inhibit $50 \%$ MCF-7 cells are low for AgNPs than the Indigofera cordifolia

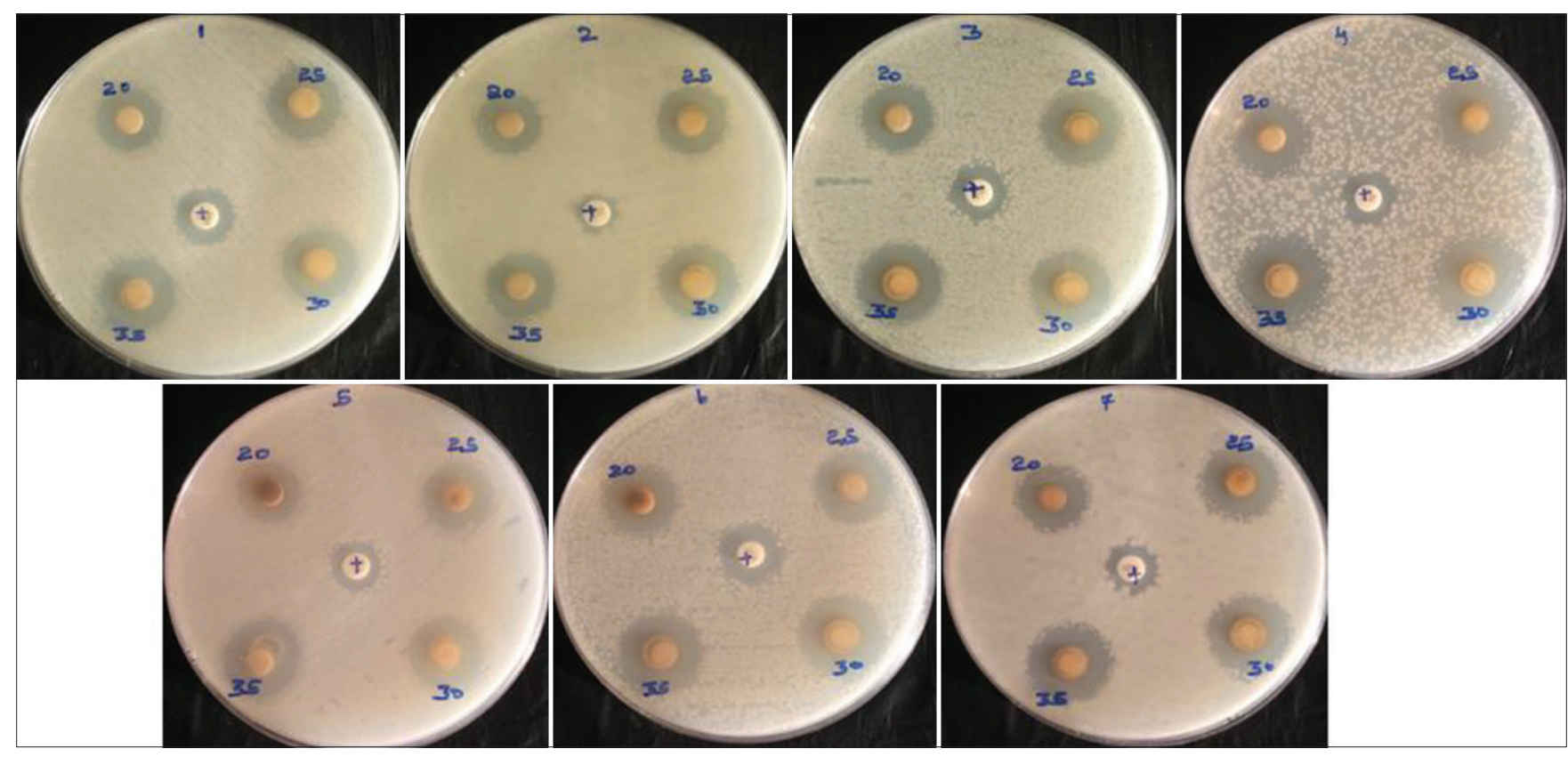

Figure 9: The antibacterial activity of silver NPs using Indigofera cordifolia leaf extract against Streptococcus aureus (2) Staphylococcus pneumonia (6) includes Escherichia coli (4), Pseudomonas aeruginosa (5), Pseudomonas vulgaris (7), Klebsiella pneumonia (1) Shigella dysenteriae (3)

Table 1. Antibacterial activity Indigofera cordifolia mediated AgNPS

\begin{tabular}{llcccrc}
\hline S. No & Name of the bacterial strains & $20 \mu \mathrm{m} / \mathrm{ml}$ & $25 \mu \mathrm{m} / \mathrm{ml}$ & $30 \mu \mathrm{m} / \mathrm{ml}$ & $35 \mathrm{~m} / \mathrm{ml}$ & Amoxicillin \\
\hline 1. & Klebsiella pneumonia & $22.32 \pm 1.21$ & $23.40 \pm 0.91$ & $25.22 \pm 0.65$ & $25.19 \pm 1.12$ & $18.22 \pm 0.39$ \\
2. & Streptococcus aureus & $21.41 \pm 0.41$ & $22.39 \pm 1.13$ & $23.33 \pm 0.33$ & $22.12 \pm 1.03$ & $13.33 \pm 0.20$ \\
3. & Shigella dysenteriae & $23.42 \pm 0.38$ & $24.32 \pm 1.02$ & $26.36 \pm 1.03$ & $27.46 \pm 0.82$ & $12.42 \pm 1.38$ \\
4. & Escherichia coli & $22.38 \pm 0.59$ & $24.29 \pm 0.36$ & $24.11 \pm 0.26$ & $26.31 \pm 0.69$ & $13.23 \pm 0.31$ \\
5. & Pseudomonas aeruginosa & $19.24 \pm 1.02$ & $21.31 \pm 0.52$ & $23.26 \pm 0.46$ & $24.36 \pm 1.22$ & $16.37 \pm 0.49$ \\
6. & Staphylococcus pneumonia & $21.37 \pm 0.81$ & $22.39 \pm 0.43$ & $24.12 \pm 1.21$ & $26.40 \pm 0.35$ & $12.41 \pm 0.56$ \\
7. & Pseudomonas vulgaris & $21.22 \pm 0.45$ & $22.36 \pm 0.13$ & $23.39 \pm 0.62$ & $6.23 \pm 0.41$ & $13.26 \pm 0.29$ \\
\hline
\end{tabular}

Mean Zone of inhibition \pm SD (in $\mathrm{mm}$ )

Table 2: MCF-7 Cells MTT assay was done following the incubation period of the plant extract, silver nitrate and two concentrations of silver nanoparticles of indigofera cordifolia

\begin{tabular}{|c|c|c|c|c|c|c|}
\hline \multirow[t]{2}{*}{ Treatment } & \multicolumn{2}{|c|}{ 12hour } & \multicolumn{2}{|c|}{ 24hour } & \multicolumn{2}{|c|}{ 36hour } \\
\hline & Viable (\%) & Inhibition (\%) & Viable (\%) & Dead Inhibition (\%) & Viable (\%) & Dead Inhibition (\% \\
\hline MCF-7 Cell+Plant Crude extract & $68.38 \pm 0.12$ & $31.00 \pm 0.10$ & $62.00 \pm 0.41$ & $36.00 \pm 0.03$ & $58.00 \pm 0.91$ & $45.12 \pm 0.02$ \\
\hline $\mathrm{MCF}-7 \mathrm{Cell}+\mathrm{AgNO}_{3}$ & $74.41 \pm 1.21$ & $26.01 \pm 0.91$ & $72.00 \pm 0.38$ & $23.02 \pm 0.12$ & $70.32 \pm 0.45$ & $24.21 \pm 1.57$ \\
\hline MCF-7 Cell+50 mg/mL AgNPs & $62.32 \pm 0.81$ & $37.10 \pm 1.02$ & $55.21 \pm 1.23$ & $45.21 \pm 0.59$ & $34.02 \pm 0.52$ & $63.21 \pm 0.3$ \\
\hline MCF-7 Cell+100 mg/mL AgNPs & $54.23 \pm 0.64$ & $46.01 \pm 1.21$ & $28.00 \pm 1.41$ & $72.20 \pm 1.15$ & $12.00 \pm 0.43$ & $88.00 \pm 1.06$ \\
\hline
\end{tabular}


leaves extract (Jacob et al., 2012; Selvi et al., 2016; Ciorîță et al., 2020; Vijayarathna \& Sasidharan,2012; Venugopal et al., 2017).

\section{CONCLUSIONS}

Ag NPs were produced from Indigofera cordifolia leaf extract using the Green method. The absorbance was centered at 420 nanometer, in contrast to the surface plasmon resonance of silver nanoparticles wavelength. XRD analysis proves that synthesized NPs retained the FCC structure and the crystalline size $28.46 \mathrm{~nm}$ for Ag NPs. The X-ray photoelectron spectrum provided the knowledge of the oxidation state of $\mathrm{Cl}$ s, $\mathrm{Ols}$ and silver $3 \mathrm{~d}$ state for silver nanoparticles. From the FESEM image, the silver nanoparticles would be seen as spherical shapes. The element composition was discovered by Energy Dispersive $\mathrm{X}$-ray analysis spectra. In the TEM result, the surface structure of silver nanoparticles was a spherical structure with a particle size of 10-30 nm. In the Fourier Transform Infrared spectrum of biosynthesized silver nanoparticles frequency was obtained at $1384 \mathrm{~cm}^{-1}$, this was due to nitrate stretching, which arises from silver nitrate. The green and yellow peaks were identified at 501 $\mathrm{nm}, 541 \mathrm{~nm}$ and $573 \mathrm{~nm}$ of the organic matrix bound to silver nanoparticles. The silver NPs have high microbicidal properties as they differentiate with the standard drug amoxicillin. The AgNPs have a bactericidal activity which can act against the bacterial cells. The produced secondary metabolites, that causes cell death.

\section{ACKNOWLEDGEMENT}

The financial support from the University Grant Commission, SERO, Hyderabad, India is gratefully acknowledged. The authors are also thankful to Management J.J. College of Arts and Science (Autonomous), Pudukkottai, Tamil Nadu. We also thank Prof. S. Navaneethan, Department of English, J.J. College of Arts and Science (Autonomous), Pudukkottai, Tamil Nadu, India for language editing.

\section{REFERENCES}

Amrithpal, S. (2006). Medicinal Plants of the World. New Delhi: Oxford and IBH Publishing Co Pvt Ltd.

Ciorîță, A., Suciu, M., Macavei, S., Kacso, I., Lung, I., Soran, M. L., \& Pârvu, M. (2020). Green Synthesis of Ag- $\mathrm{MnO}_{2}$ Nanoparticles using Chelidonium majus and Vinca minor Extracts and their In Vitro cytotoxicity. Molecules, 25(4), 819. https://doi.org/10.3390/ molecules25040819

Coates, J., \& Meyers, R. A., (2000). Encyclopedia of analytical chemistry, John Wiley \& Sons Ltd, Chichester. Pp.10815-10837.

Edison, T. N., Lee, Y. R., \& Sethuraman, M. G. (2016). Green synthesis of silver nanoparticles using Terminalia cuneata and its catalytic action in reduction of direct yellow-12 dye. Spectrochimica acta. Part $A$, Molecular and Biomolecular Spectroscopy, 161, 122-129. https:// doi.org/10.1016/j.saa.2016.02.044

Gunasekaran, B \& Shinnaraj, S., (2009). Preliminary phytochemical screening and Antihelmintic activity of Indigofera tinctoria. International Journal of Drug Development and Research, 1, 157-160.

Jacob, S. J., Finub, J. S., \& Narayanan, A. (2012). Synthesis of silver nanoparticles using Piper longum leaf extracts and its cytotoxic activity against Hep-2 cell line. Colloids and Surfaces. B, Biointerfaces, 91 , 212-214. https://doi.org/10.1016/j.colsurfb.2011.11.001

Kaushik, V. K., (1991). XPS core level spectra and Auger parameters for some silver compounds. Journal of Electron Spectroscopy and
Related Phenomena, 56(3), 273-277. https://doi.org/10.1016/03682048(91)85008-H

Li, S., Shen, Y., Xie, A., Yu, X., Qiu, L., Zhang, L., \& Zhang, Q. (2007). Green synthesis of silver nanoparticles using Capsicum annuum L. extract. Green Chemistry, 9, 852-858

Liao, C., Li, Y., \& Tjong, S. C. (2019). Bactericidal and Cytotoxic Properties of Silver Nanoparticles. International Journal of Molecular Sciences, 20(2), 449. https://doi.org/10.3390/ijms20020449

Mohd Yusof, H., Mohamad, R., Zaidan, U. H., \& Abdul Rahman, N. A. (2019). Microbial synthesis of zinc oxide nanoparticles and their potential application as an antimicrobial agent and a feed supplement in animal industry: a review. Journal of Animal Science and Biotechnology, 10, 57. https://doi.org/10.1186/s40104-019-0368-z

Rai, M., Yadav, A., \& Gade, A. (2009). Silver nanoparticles as a new generation of antimicrobials. Biotechnology Advances, 27(1), 76-83. https://doi.org/10.1016/j.biotechadv.2008.09.002

Raveendran, P., Fu, J., \& Wallen, S. L. (2003). Completely "green" synthesis and stabilization of metal nanoparticles. Journal of the American Chemical Society, 125(46), 13940-13941. https://doi.org/10.1021/ ja029267j

Ravichandran, K., \& Ravichandran, R. (2008). Protective effect of flavanoidal fraction of Indigofera tinctoria on Benzopyrene induced Lung carcinogenicity in Swiss Albino mice. International Journal of Cancer Research, 4(3), 71-80. https://doi.org/10.3923/ijcr.2008.71.80

Renukadevi, K. P., \& Sultana, S. S. (2011). Determination of Antibacterial, Antioxidant and Cytotoxicity effect of Indigofera tinctoria on Lung cancer cell line NCl-h69. International Journal of Pharmacology, 7, 356-362. https://doi.org/10.3923/ijp.2011.356.362

Sánchez-López, E., Gomes, D., Esteruelas, G., Bonilla, L., Lopez-Machado, A. L., Galindo, R., Cano, A., Espina, M., Ettcheto, M., Camins, A., Silva, A. M., Durazzo, A., Santini, A., Garcia, M. L., \& Souto, E. B. (2020). Metal-Based nanoparticles as antimicrobial Agents: An overview. Nanomateria/s, 10(2), 292. https://doi. org/10.3390/nano10020292

Saravanakumar, A. (2009). Evaluation of the antinociceptive properties from Indigofera tinctoria leaf extracts. Journal of Pharmaceutical Sciences and Research, 1, 31-37.

Sasidharan, N. (2004). Biodiversity documentation of Kerala part 6: Flowering Plants, Kerala. Peechi: Forest Research Institute. 261.

Selvi, B. C. G., Madhavan, J., \& Santhanam, A. (2016). Cytotoxic effect of silver nanoparticles synthesized from Padina tetrastromatica on breast cancer cell line. Advances in Natural Sciences: Nanoscience and Nanotechnology, 7(3), 035015. http://dx.doi.org/10.1088/2043$6262 / 7 / 3 / 035015$

Shah, M., Poinern, G. E. J. \& Fawcett, D. (2016). Biogenic synthesis of silver nanoparticles via indigenous Anigozanthos manglesii, (red and green kangaroo paw) leaf extract and its potential antibacterial activity. International Journal of Research in Medical Sciences, 4, 3427-3432. https://doi.org/10.18203/2320-6012.ijrms20162306

Sirelkhatim, A., Mahmud, S., Seeni, A., Kaus, N., Ann, L. C., Bakhori, S. Hasan, H., \& Mohamad, D. (2015). Review on zinc oxide nanoparticles Antibacterial activity and toxicity mechanism. Nano-micro letters, 7(3) 219-242. https://doi.org/10.1007/s40820-015-0040-x

Thuesombat, P., Hannongbua, S., Akasit, S., \& Chadchawan, S. (2014). Effect of silver nanoparticles on rice (Oryza sativa L. cv. KDML 105) seed germination and seedling growth. Ecotoxicology and Environmenta/ Safety, 104, 302-309. https://doi.org/10.1016/j. ecoenv.2014.03.022

Venugopal, K., Rather, H. A., Rajagopal, K., Shanthi, M. P., Sheriff, K., Illiyas, M., Rather, R. A., Manikandana, E., Uvarajan, S., Bhaskar, M. \& Maazaf, M., (2017). Synthesis of silver nanoparticles (Ag NPs) for anticancer activities (MCF 7 breast and A549 lung cell lines) of the crude extract of Syzygium aromaticum. Journal of Photochemistry and Photobiology B: Biology, 167, 282-289. https://doi.org/10.1016/j. jphotobiol.2016.12.013

Vijayarathna, S., \& Sasidharan, S. (2012). Cytotoxicity of methanol extracts of Elaeis guineensis on MCF-7 and Vero cell lines. Asian Pacific Journal of Tropical Biomedicine, 2(10), 826-829. https://doi.org/10.1016/ S2221-1691(12)60237-8

Wang, L., Hu, C., \& Shao, L. (2017). The antimicrobial activity of nanoparticles: present situation and prospects for the future. International Journal of Nanomedicine, 12, 1227-1249. https://doi.org/10.2147/IJN.S121956

Warrirer, P. K., Nambiar, V. P. K., \& Ramankatty, C. (2007). Indian medicinal plants. Chennai: Orient Longman Private Limited; 210-213. 